A Practical Guide for

Civil Society Organisations

in Lebanon towards

\title{
GENDER MAINSTREAMING
}
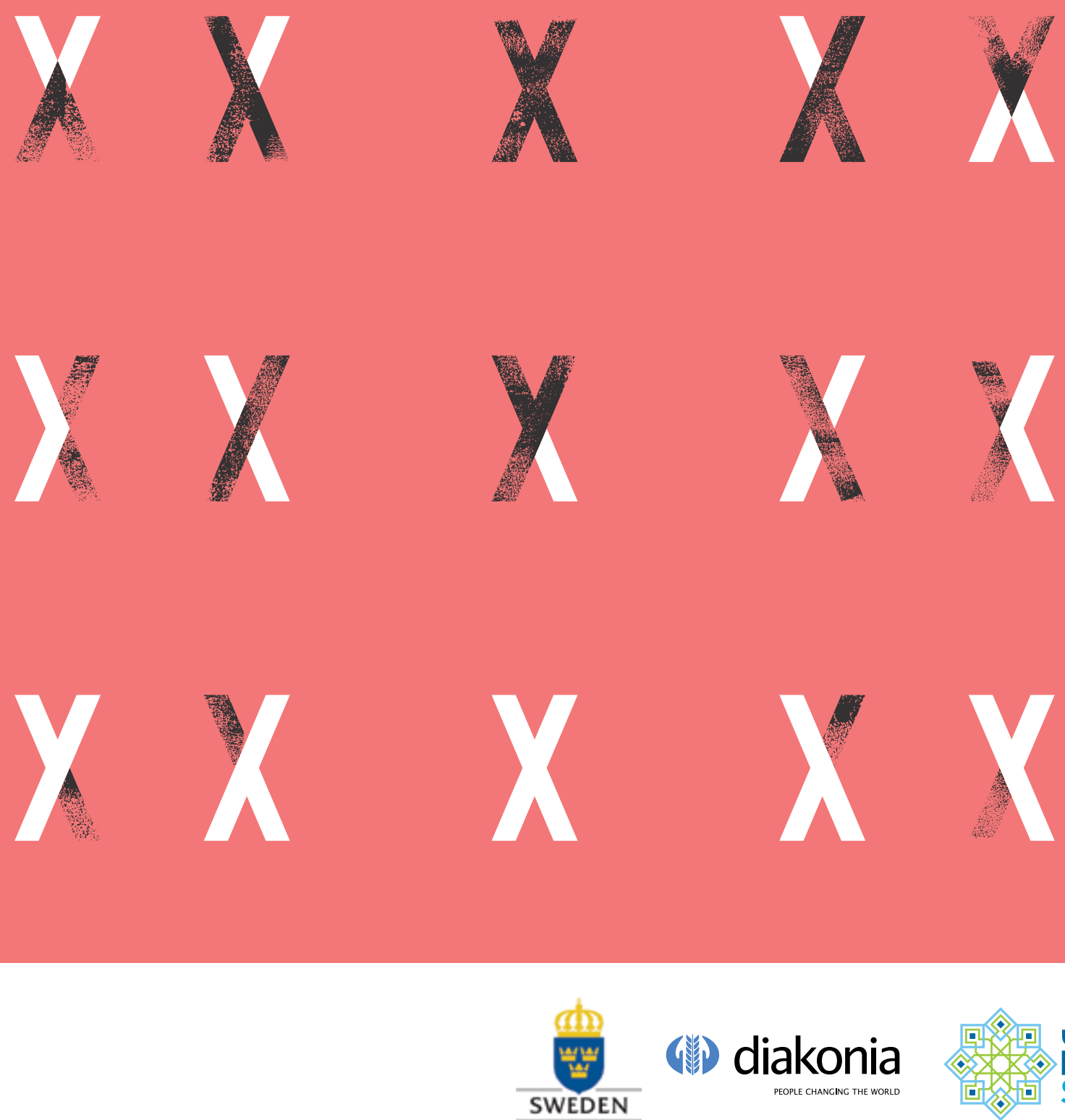

(㗂) diakonia PEOPLE CHANGING THE WORLD

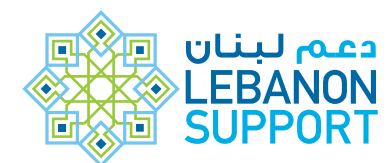




\section{Acknowledgements}

Lebanon Support would like to thank our various interlocutors for taking part in this research and for sharing their experiences. We are also grateful for the peer-reviewers' insightful feedback and discussion. In particular, we would like to thank Manar Zeaiter, Doreen Khoury, and Raida Hatoum.

\section{Team}

Research and Project Officer: Amreesha Jagarnathsingh

Research Assistants: Floriane Soulié, Sarah ElMasry

Research Intern: Asser Khattab

Civil Society Incubator Programme Manager: Rola Saleh

Director of Publications: Léa Yammine

Head of Research: Marie-Noëlle AbiYaghi

Copy Editor: Muriel N. Kahwagi

Layout and Design: Nayla Yehia

The views expressed in this publication are solely those of the author(s) and do not necessarily reflect the views of Lebanon Support or its partners.

Lebanon Support @ Beirut, December 2017.

No part of this publication may be reproduced, distributed, or transmitted in any form or by any means, including photocopying, recording, or other electronic or mechanical methods, without the prior written permission of the publisher, except in the case of brief quotations and referencing in critical reviews and articles, and certain other noncommercial uses permitted by copyright law. 
INTRODUCTION

GENDER

MAINSTREAMING

MODULES

I Gender analysis

II Implementation:

Define, design, and integrate

III Monitoring and evaluation

CONCLUSION
3

4 Back to basics: Gender 101

7

8 How to? Gender analysis methods

Quantitative data $\square$ 8

Qualitative data $\square$ \& 8

14 External context analysis: Barriers and constraints prohibiting gender equity in Lebanon

17 Internal context analysis: Gender analysis at the organisational level

Internal policies $\square$ \&

21 Communication analysis $\square 8 Q$

25 Needs assessment $\square \mathrm{Q} Q$

28 Gender mainstreaming at the organisational level Internal policies and accountability

Addressing external needs: A better work-life balance

$\square$ Q ब

35 Developing inclusive communication policies 8

37 Gender mainstreaming in programmes, projects, and budgets $\square \& \otimes$

41

41 Baseline studies: A tool for monitoring projects

42 Feedback mechanism $\square$ \&

44 


\title{
PRACIICE WHAT YOU PREACH
}

\author{
$\beta($ Gender mainstreaming is \\ at the heart of what we do.
}

Organisations, companies, and civil society groups should endorse it and make it into a habit-adopt it as natural behaviour. We want to achieve fair representation and equal participation. I think this will improve the outcome of the work we do, [which then] becomes more just, and more fair [...]. This actually serves society as a whole. [...] If you want people to follow your example, and to raise awareness, you have to practice what you preach. ${ }^{1}$ Representative of a prominent feminist civil society organisation in Lebanon.

\section{$\mathcal{B}$ to work on this issue'-no. It's} about saying, 'I have to start working on myself, and on the organisation itself.' [...] It's about time that whatever change we hope to see in the community must first take place in our own homes, or at the organisations we work in. Otherwise, we don't actually want change, but we're just donor oriented. ${ }^{2}$ Representative of an international development organisation with a special focus on gender issues. 


\section{Introduction}

Gender equity is a fundamental human right, as stated in the Universal Declaration of Human Rights. ${ }^{3}$ It is a central issue in addressing global development, and a driving force in achieving social and economic goals. ${ }^{4}$

First introduced at the Third United Nations World Conference on Women in Nairobi in 1985, ${ }^{5}$ gender mainstreaming has been adopted since the Fourth United Nations World Conference on Women in Beijing in 1995, where it was highlighted as one of the most effective strategies in promoting gender equity. ${ }^{6}$ On an organisational level-taking into consideration a gender perspective at the heart of an organisation's work and structure-gender mainstreaming is a powerful tool to challenge the dominant male-centered paradigm, and push towards gender equality. ${ }^{7}$

In order to gender mainstream, it is important to understand how being a woman, man, or gender non-conforming individual affects one's access to resources, opportunities, and rights. ${ }^{8}$ Moreover, individuals' experiences and perspectives should be incorporated into recommendations for structural change and standard-setting. ${ }^{9}$

This Gender Manual is a practical guide for civil society organisations in Lebanon that wish to enhance gender equity in their practices and policies. Far from being exhaustive, this manual contains practical guidelines that can help to both gain a better understanding of gender-sensitive topics, as well as to integrate and implement them in internal processes, action plans, and organisational structures and policies. It is informed by the findings of a series of meetings and consultations with various stakeholders engaged in gender issues. It is worth noting, however, that the guidelines provided in these pages are general, and should thus be tailored and incorporated depending on the organisation's type, specialisation, and focus. ${ }^{10}$

This Gender Manual is developed by Lebanon Support in collaboration with Diakonia, as part of Lebanon Support's Gender Equity Network, which is part of Lebanon Support's Civil Society Knowledge Center. The Gender Equity Network (civilsociety-centre.org/gen) aims to enhance local and national capacities' access to-and development of-knowledge- and evidence-based research, information, and literature on gender issues and concerns. The manual also falls within Lebanon Support's Civil Society Incubator, which provides tailored support and mentorship to local civil society and public action initiatives, organisations, and projects. 


\section{Back to Basics: Gender 101}

Gender awareness is instrumental to the process of achieving gender equity, but some organisations may not have the proper tools to achieve it. As a first step, therefore, it is important for the people in your organisation to have a general understanding of the basic concepts in the field of gender; of the most frequently used terms; as well as their exact definition. This section will help you gain a strong grasp of the basic gender terms, which can be relevant in work settings. ${ }^{11}$

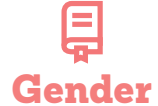

refers to the socially and culturally constructed differences between women and men; this term should be distinguished from "sex," which refers to their biological differences. The social constructs of gender vary across different cultures and time periods. Gender is shaped by the conception of roles, relationships, and power.

\section{Gender identity}

is not to be equated with sexual orientation per se; it refers, rather, to how people define or locate themselves on the gender spectrum. Gender identities can be female, male, and gender non-conforming (see "Gender non-conforming" below). ${ }^{12}$ It is worth noting, here, that gender identities often intersect with vulnerabilities experienced by minorities, which encompass-but are not limited to-sexual minorities, HIV-positive people, disabled or elderly people, ethnic minorities, migrant workers, refugees or people with low income (see the box on Intersectionality in the next section).

\section{틀 \\ Gender non-conforming}

is a self-identification term used by people who do not identify with the traditional and binary division of gender identity as purely masculine or feminine (also known as "cisgender"). As such, gender non-conforming-also referred to as non-binary or genderqueer-can be viewed as a "catch-all category," which can encompass transexual, intersex, gender fluid, agender, etc. Gender non-conforming individuals are usually represented in LGBTIQA movements and engage in gender advocacy work, as they challenge binary gender norms.



refers to the biological and physiological differences between females and males.

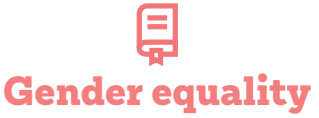

means that every person, regardless of gender, should have equal rights and access to opportunities, services, resources, benefits, participation, and responsibilities in both private and public spheres. It is important to note, here, that being given equal chances does not necessarily result in equal outcomes for women and men (see "Gender equity" below).

\section{Gender equity}

takes gender equality one step further It entails recognising the differences between genders, and acknowledging their different needs, constraints, and aspirations. Only then can equal chances and equal outcomes be created. This process of ensuring fair treatment is called gender equity.

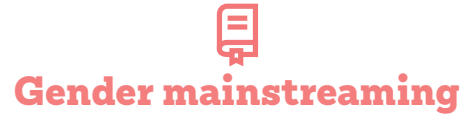

is the process of adopting a gender-inclusive perspective across different types of activities or projects. It can be viewed as a means of achieving gender equality. Gender mainstreaming involves the examination, reorganisation, improvement, and evaluation of measures, legislations, and policies in cultural, societal, political, and economic domains, with the purpose of incorporating gender equality in all policies.

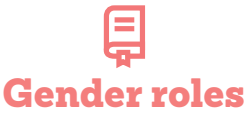

are societal norms that are shaped by what is generally considered to be acceptable, appropriate, or desirable for each sex. These norms are often conditioned very early on in life, and are reflected in political, social, and productive spheres. 


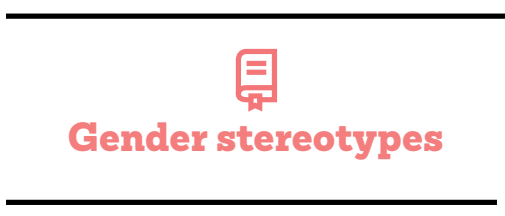

Stereotypes are structured sets of beliefs about the tasks, behaviours, and roles of a specific social group. Gender stereotypes are "biased and often exaggerated images of women and men, which are used repeatedly in everyday life" 13 on the basis of preconceived prejudices.

\section{Gender sensitivity}

refers to being aware of traditional gender roles, as well as existing gender differences and inequalities. Gender sensitivity also entails implementing gender equality into strategies and actions.

\section{Gender discrimination}

is any distinction, exclusion, or restriction made on the basis of sex or gender, with the purpose of impairing or nullifying the recognition, enjoyment, or exercise of human rights and fundamental freedoms in the political, economic, social, cultural, and civil fields (among others), regardless of one's marital status. ${ }^{14}$ Discrimination can also occur on the grounds of race, age, or other personal characteristics that can lead to differential treatment based on false assumptions and stereotypes.

\section{E \\ Gender-based violence (GBV)}

is different from other types of violence in that it is inflicted on another person based on their sex or gender identity and/or their "gendered expectations." Gender-based violence can be physical, sexual, emotional, or economic in nature (e.g. acquisition of income by force). Though women and younger girls are seen as the primary victims of GBValso referred to, in this case, as Violence

Against Women (VAW) - LGBTIQA people, men, and younger boys can be targeted, as well.

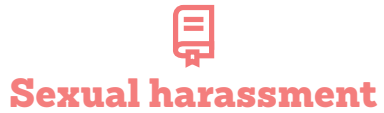

is a form of discrimination denoting undesired approaches with a sexual nature. Sexual harassment may include rape, as well as verbal, non-verbal, written, visual, psychological, and physical threats. ${ }^{15}$

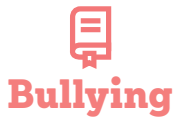

refers to conduct that aims at intimidating or harming another person, be it physically or emotionally. This behaviour is usually characterised by the repetition of verbal, physical, or implicit threats, perpetrated by individuals who use their power (such as physical strength, popularity, information, position, etc.) to control or harm a less powerful other. Bullying can consist of, but is not limited to: teasing, name-calling, threatening or blackmailing, spreading rumors, public shaming, physical hurt, or property damage. ${ }^{16}$ is an approach to development policies that recognises the socially constructed and imbalanced power relations between men and women, and which seeks to question "existing gender roles." 17 This approach was conceived out of the criticism against the Women in Development (WID) and Women and Development (WAD) approaches. WID and WAD call for the integration of women in development processes by creating "income-generating opportunities," which would then improve women's economic rights without having a strategic assessment of gender needs or the power imbalance between men and women. ${ }^{18}$

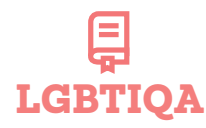

is an acronym which stands for "lesbian, gay, bisexual, trans, intersex, queer, and asexual;" another "Q" is sometimes added to include "questioning people." 19 The acronym can change and be extended depending on the purpose for which it is used, as well as the organisation that employs it. ${ }^{20}$ This abbreviation is often used in relation to discriminations and inequalities that individuals have to endure because of their sexual preference and/or gender identity, against the backdrop of prevalent heteronormativity. ${ }^{21}$ 
Below are some questions that can help you to identify gender inequalities within your organisation:

Is your team aware of gender inequalities?
Are your team members

gender-sensitive?

\section{TIPS ON HOW TO GET STARTED}

If you haven't checked off the items in the checklist above, it is crucial to provide your team with knowledge on these basic concepts, and to raise awareness on gender-related issues within your organisation. You can do this by:

Organising training sessions and workshops.

Organising collaborative sessions to identify inequalities in your daily work and behaviour regarding gender.

Provide background information and educate members of your organisation on commemoration days such as International Women's Day (8 March), World AIDS Day (1 December), Gay Pride events (which vary in different countries), International Migrants' Day (18 December), etc.

\section{GENDER 101 EXERCISES: CRITICAL THINRING}

What is gender?

In a group, discuss the difference between "gender" and "sex." Does your organisation have policies that only reflect sex, but not gender? Make a list of these policies and discuss how you can broaden them to include gender.

\section{What is a gender stereotype?}

In a group meeting, ask the attendees to make a list of words usually used to describe women and men. Discuss common assumptions about women and men that are induced by these stereotypes, then discuss how these assumptions shape the organisation of work and the distribution of tasks. 


\section{Gender Mainstreaming Modules}

Gender mainstreaming can be divided into three steps: analysis, design, and evaluation. ${ }^{22}$

I

Gender Analysis

First, analyse your organisation's

strengths and weaknesses in gender mainstreaming.

\section{II}

Implementation: Define, design, and integrate

Second, use this information to design gender mainstreaming procedures at the organisational level, as well as for individual programmes, projects, and budgets.

\section{III}

Monitoring and evaluation

Third, monitor and evaluate your gender mainstreaming activities. This will help you to assess the impact and progress of your gender mainstreaming policies. 


\section{Gender analysis}

The first step towards creating gender mainstreaming is to analyse the barriers to-and constraints of-achieving gender equity in your work environment (section 1.2). In Lebanon, this analysis should be carried out at both local and national levels. This means that you must take into account your environment, laws, policies, cultural practices, etc., to understand how they can collectively impact gender mainstreaming in the workplace.

The second step is to examine internal policies at the organisational level (section 1.3). This includes analysing the internal policies (section 1.3.1) and communication and visibility strategy (section 1.4) of your organisation, as well as conducting a needs assessment (section 1.5). Overall, these steps allow you to gain a better understanding of the barriers you face in gender mainstreaming at work, which can inform a sounder strategy towards gender equity.

Before expounding on these steps, however, the manual will provide an overview of gender analysis methods, which you can use during this process.

\section{1}

\section{How to? Gender analysis methods}

Gender analysis includes a critical evaluation of a variety of factors, including the role of women, men, and gender non-conforming individuals in your organisation. Gender analysis also examines the prevailing dynamics amongst team members, which may be shaped by cultural, social, and economic factors. This analysis of relations, roles, and responsibilities is a requisite for understanding the different power dynamics within an organisation, and can play a role in identifying what makes a person vulnerable.

For the gender analysis to be exhaustive, you need to gather both quantitative and qualitative data. This will allow you to establish gender indicators which, in turn, enable your organisation to compare challenges experienced by women, men, and gender non-conforming individuals. The collected data may provide you with insights on how to improve your gender mainstreaming activities. 


\section{Quantitative data}

In order to achieve gender-sensitive programming, gender-, origin-, and age-disaggregated data should be collected. ${ }^{23}$ As the data contains sensitive information about your organisation, make sure to take the necessary measures to guarantee the confidentiality of the data in storage and usage.

Sex-disaggregated data makes a distinction between women and men in the processes of planning, implementation, monitoring, and evaluation. Disaggregating data by sex, will provide you with insights on the number of women and men in different roles and with different responsibilities. However, sex-disaggregated data does not include individuals who identify as gender non-conforming, ${ }^{24}$ which is why we recommend that you disaggregate data based on gender, rather than sex. Gender-disaggregated data, however, has proven to be more difficult to collect than sex-disaggregated data, since individuals may not feel comfortable to divulge their gender identity in the workplace. For this reason, there has been an ongoing effort from scholars and experts to develop new statistical methods and scales that encompass the diverse gender identities. ${ }^{25}$ One method that you could adopt in your organisation would be to to anonymously let employees self-identify their gender. Ideally, the answer to the question "What is your gender?" would entail the following option(s):

- Male

- Female

- Non-binary

- Prefer to self-describe

- Prefer not to say

For the difference between gender and sex, please refer to Back to basics: Gender 101.

Gender-, origin-, and age-disaggregated data typically includes quantitative data. For instance, the number of women, men, and persons with non-conforming gender identification would be charted against other background information, such as wage, benefits, extended contracts, etc. Data analysis of this breadth and depth is crucial in order to identify and address different dimensions of discrimination. This in turn can give insight into the intersectional discrimination experienced by employees in your organisation.

\section{INTERSECIONALITY}

Intersectionality is a term often used in the field of gender. It

emphasises the ways through which social identities (sexual orientation, gender identity, social class, etc.) intersect and intertwine with different types of

discrimination-against ethnicity, religion, or sex ${ }^{26}$ for example. The interdependent relationship between one's social identity and discrimination creates an additional layer of discrimination.

For example, dark-skinned women are perceived as more vulnerable than both light-skinned women and dark-skinned men. This is because dark-skinned women face a dual discrimination: first, for being a woman (gender discrimination), and second, for being dark-skinned (racial discrimination). This intersectionality induces a third type of discrimination ${ }^{27}$ whereby being both a women and dark-skinned collide to form a unique type of discrimination. This third layer of discrimination only exists in the case of intersecting identities, whether racial, gender-related, or otherwise.

More specifically, gender identities as female, male, and gender non-conforming often intersect with other types of discrimination that are specific to sexual preference, income class, nationality, race, disabilities and diseases (for example, sexually transmitted infections; HIV), and/or religion. 
Below are some questions to help you get started with quantitative data collection:

Gender: How many women, men, and gender non-conforming individuals are employed in the organisation? What is the number of women, men, and gender non-conforming individuals in different positions (senior management, management, administrative positions, etc.)? Does your organisation abide by a gender quota?

Ethnicity: How many employees come from a variety of racial backgrounds?
Age: What different age groups can be distinguished? Is every age group (18-64) represented in different types of positions?

General: Do employees of the same position get the same income (regardless of their gender, ethnicity, religion, etc.)? What is the percentage of people who have access to healthcare? Do all employees receive the same benefits?

\section{TIPS ON COLLECTING QUANTITATIVE DATA}

Quantitative data can be measured and is collected through questionnaires, surveys, and observations. When collecting this data, be sure to:

Observe specific behaviour from a gender-, origin-, and age-disaggregated lens: make sure to collect the figures that can reflect the discrimination your employees may be facing due to their gender identity

Ask the interviewees close-ended questions

Ensure employees' anonymity when you collect information, so that they do not feel intimidated, but rather comfortable, to share their experiences
Collect representative data: include as many people as possible, and make sure that the interviewed group is as representative of the organisation as possible

Pay attention to the design of your questions:

ᄂ_ Avoid using jargon to make sure everyone understands the question.

L_ Address only one issue per question.

ᄂ Be neutral in both tone and vocabulary to ensure that your questions are not biased towards a particular answer. 


\section{Qualitative data}

Even if your organisation has an equal number of women and men, as well as a significant number of gender non-conforming individuals, ${ }^{28}$ this is only one step towards achieving gender mainstreaming.

An equally important step is understanding the differences between women, men, and gender non-conforming individuals. This includes control and power, such as the equal division of roles and responsibilities, access to resources and assets, space to negotiate salaries, terms and conditions, etc. ${ }^{29}$ It is also important to analyse power relations and dynamics between employees, as well as between different target groups and partners.

In addition, qualitative analysis consists of observing the turnover rate within the organisation; in other words, how frequently do employees leave an organisation-or a certain position within the organisationand have to be replaced? ${ }^{30}$ For example, a low turnover rate might indicate that employees do not have much room for growth within a particular organisation. At times, this can also point to non-transparent practices hindering employees' career advancement.

Lastly, qualitative analysis also comprises investigating how organisations portray and represent themselves through their communication and visibility strategy. This includes the stances they take regarding issues related to vulnerable groups, such as domestic workers, migrant workers, or refugees.

\section{Qualitative gender equity}

$3\left(\begin{array}{l}\text { Some organisations state that they have } \\ \text { a gender perspective or that they gender }\end{array}\right.$ mainstream because they have [employed] 50\% women and 50\% men. For someone like me who works in a feminist organisation, that's not what gender equality is about; we should use gender equity as a tool to reach gender equality. [...] Gender equity is about providing opportunities and resources, etc. ${ }^{31}$

Representative of a leading women's organisation working in Lebanon 
Below are some questions to help you get started with collecting qualitative data:

Power and control: Do employees have the same roles and responsibilities? Are resources and assets equally available to all employees and target groups? Do they have equal negotiation of space, autonomy, influence, and control/ power? Are people of different genders equally consulted and involved in decision-making and programmatic work?

Frequency of change: Does the turnover rate in the organisation make room for younger employees to occupy leadership positions? After how many years of employment, on average, do people resign? What are the main reasons to resign?
Representation and communication: Are women and/or gender non-conforming individuals participating less actively in team meetings? Are they more frequently interrupted than men? Do they sit on the edges of the room/table? Do men speak louder than women and/or gender non-conforming individuals in meetings?

Other: Are women, men, and gender non-conforming individuals equally accountable for their actions? Do they have the same opportunities for getting trained or promoted?

\section{TIPS ON HOW TO COLLECT QUALITATIVE DATA}

One-on-one interviews, focus groups, and observation are the three main tools for collecting qualitative data. When collecting this data, be sure to:

Look for and ask about differences between different gender identities' experiences, roles, needs, and priorities.

Consult with and talk to women, men, and gender non-conforming individuals-separately and together-to give them a chance to voice their concerns, and to understand group dynamics, respectively.

Consider that some interviewees may feel intimidated or restrained when it comes to expressing their concerns. You can anticipate this by allowing an external gender expert to conduct the interviews. If you are conducting the interviews without external help, your organisation should provide an option for interviewees to choose a male, female, or gender non-conforming interviewer.

Pay attention to implicit cues, such as body language or voice tone.

Check whether the interviewees' are solely community or group leaders. ${ }^{32}$ Ideally, everyone in the organisation should be interviewed, but if this is not feasible, ensure that your focus group is representative and reflects gender, race, and age differences. 
The goal of this exercise is to highlight the roles assigned to women, men, and gender non-conforming individuals in the organisation. It also shows how tasks (work and daily chores at the office) correspond to stereotypes.

Q In a group meeting, appoint three persons to note down the following without informing the rest of the team:

ـ How many times do women vs. gender non-conforming individuals vs. men speak?

ᄂ_ How long do women vs. gender non-conforming individuals vs. men speak for?

ـ How many times are women vs. gender non-conforming individuals vs. men interrupted?

Q For each member of the organisation, establish a daily schedule of every task that they undertake for one week.

NOTES 
External context analysis: prohibiting gender equity in Lebanon

In order to gender mainstream, organisations should-upon collecting quantitative and qualitative data-consider the barriers and constraints prohibiting gender equity through an external context analysis; this allows you to measure the external factors inhibiting gender equity in the organisation. These vary across different countries, cultures, and generations. In Lebanon-despite considerable progress and increased awareness_-inequalities among women, men, and gender non-conforming individuals continue to persist in a number of fields, as patriarchy ${ }^{33}$ is highly entrenched in Lebanese institutions and society. As such, legally upheld economic, social, and cultural frameworks impact the daily lives of the population and perpetuate inequalities that colour and contour the relationships between different social groups. Before examining these, however, it is important to note that women are rarely implicated in the decision-making process in Lebanon; if they are, their role often takes on a symbolic dimension. ${ }^{34}$ This is reflected in the fact that, out of 142 countries, Lebanon is ranked

\section{BOX: DID YOU KNOW?}

Formal and informal practices generally impede women from equal participation in decision-making:

- Research shows that even in small, non-hierarchical collectives working in the field of gender, exclusionary practices still exist and tend to favour men over women. 35

- Other research shows that even within some feminist organisations, non-inclusive practices are persistent and tend to favour some members over the wider base. ${ }^{36}$

second worst for women's participation in politics, with no female ministers in the government and a mere 3 percent of women holding parliament seats. ${ }^{37}$ On a more individual level, Article 54 of the 1926 Lebanese Civil Code considers a woman's testimony to be worth half of a man's. ${ }^{38}$

Below are some laws that you need to be familiar with in order to conduct your external context analysis in Lebanon:

Personal Status Laws: Allow religious courts of 18 recognised sects to oversee matters such as marriage, divorce, and property rights, in place of the state. This often acts as an enabler for cultural, patriarchal practices within religious systems, which are highly discriminatory against women.

Nationality Law: Prohibits Lebanese mothers to pass on their nationality to their spouses or children. ${ }^{39}$

Lebanese Labour Law: Restricts the employment of children under 13 years old, adolescents, and women in occupations that entail heavy or dangerous work. For example, Article 27 of the Lebanese Labour Code considers some occupations to be purely "masculine," forbidding women to work in occupations concerned with-among others - "the production of alcohol and all other alcoholic drinks, cutting up animal carcasses, and work involving electric accumulators and driving engines." 40 Another example is Article 34, which prescribes a one-hour break after five hours of consecutive work for women, and 6 hours of consecutive work for men. Furthermore, Article 59 gives women who have been employed for over a year the right to take a leave "because of marriage," 41 and still get their end of job indemnities, while men are not granted the same right.

National Social Security Law: Within the National Social Security Fund, some benefits and protection are still not available to women. 42 With regards to parental leave, maternity leave was extended from seven to ten weeks in 2014,43 though this figure is still significantly lower than the 14-week-parental leave prescribed by the International Labour Organisation. ${ }^{44}$ Paternity leave, on the other hand, is nonexistent in Lebanon. 
Violence and sexual harassment: Legislation explicitly criminalising sexual assault and harassment, notably in the workplace, is still absent in Lebanon. In fact, up until its abolishment on August 15, 2017, rapists could avoid criminalisation by marrying their victims under Article 522 of the Lebanese Penal Code. ${ }^{45}$

Same-sex conduct: Lastly, it is worth noting that same-sex intercourse is still criminalised in Lebanon, according to article 534 of the Penal Code.

In addition to learning these laws, it is important to gather information on your work sector in order to conduct your external context analysis. Understanding sector dynamics allows to fully understand the constraints pertaining to employee protection and discrimination. For example, some sectors, such as domestic and agricultural work, both of which host a significant number of (female) migrant workers, are not protected by the Lebanese Labour Code. These sectors' workers are thus particularly vulnerable to gender discrimination.

The aforementioned examples illustrate how inequalities between women and men persist in Lebanon, and how certain laws seem to implicitly encourage women to prioritise household and family duties. Gaining a better understanding of different cultures and customs within your environment can thus contribute to your external context analysis.

\section{Maneuvering within cultural constraints}

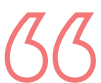

\section{When we first started working with the}

Palestinian community, for example, we didn't just say, 'we want to focus on violence against women.' The Palestinian community in Lebanon is a conservative one, in which the family unit plays an important role; it's not possible for strangers to intervene in private matters. This is why we didn't just talk about violence against women, so that they wouldn't feel that this project is against men; we talked about family violence instead. At a later stage, having worked together for a long time, we started discussing violence against women. Then, slowly, we began tackling the issue of women's rights.
We worked on raising awareness about violence, discrimination, women's rights. [It was only after that, that] we opened counseling centres to receive female survivors of violence, and introduced the presence of psychologists.

Before that, even the very mention of a therapist was like telling someone that they're crazy. So we introduced them gradually, and now it's much more acceptable within the community to mention mental health and similar issues. Then, we started talking about taboos; sexual harassment, for example. At first, it was impossible to talk about sexual harassment. People would think that we were infiltrating their culture or way of life. [....] When an organisation wants to work in the field of gender, it has to have a strong understanding of the community within which it's working, and tailor its work accordingly. 46 Representative from a leading local feminist organisation working with Palestinian women

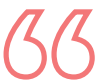
One of our partners had a project in an area where two political groups have historically been opposing one another. This project aimed to bridge the gap between various Lebanese communities and organise a project that brings them together. So, they established a recreational centre, which only men attended. This is an example of conflict-sensitive interventions, but they have to be gender-sensitive or culturally sensitive too. And of course, they didn't want to dedicate different days just for women or men. So these interventions, which were supposed to bridge differences [between different social or political groups], didn't take gender into account. They ended up doing more harm than good. 47 Representative of an international development organisation with a special focus on gender issues 
Along with different staff members, analyse the sector you work in.

L Are there any laws, policies, or cultural practices that constrain gender equity in the sector you work in?

ᄂ What are the (gender) stereotypes within the sector?

ـ Do all genders have equal access to work in this area? If not, can you identify why?

ـ Identify the types of protection procedures that can be implemented in your sector of work in order to ensure a safe working environment for all gender identities.

NOTES 


\section{Internal context analysis: Gender analysis at the organisational level}

Now that you have collected your quantitative and qualitative data, and conducted external context analysis, it is time to analyse the internal environment and resources at the organisational level, in order to formulate gender equity objectives that cater to your organisation's needs. This includes analysing your internal policies, your communication and visibility strategy, and the language used by your staff and personnel. The last step of this process, which consists of an internal context analysis, entails conducting and analysing the results of a needs assessment.

The following subsections will present more detailed guidelines on how you can analyse the internal bylaws and the communication policies within your organisation.

\section{Internal policies}

The Lebanese Labour Law does not offer any pro-

tection against discrimination in the workplace.

Rather, it requests every organisation with at least 15 employees to establish bylaws and statutes framing workers' behaviours (Article 66). ${ }^{48}$ Therefore, organisations must analyse their internal policy documents to ensure that they convey diversity and inclusivity, and provide internal mechanisms to address and inspect discrimination in its different forms. Internal policy documents that must be analysed to promote diversity and fight discrimination include, but are not limited to:

- The organisational Code of Conduct

- Statutes and bylaws

- Recruitment strategies

- Contracts and Terms of Reference

- Salary scales and other salary-related documents

- Remuneration policies

- Communication and visibility strategy

- Appraisal assessments

- Dismissal processes

The policies should aim to create a gender-sensitive working environment, enable victims of discrimination to denunciate inappropriate conduct, and allow organisations to investigate and take corrective measures against discrimination. ${ }^{49}$ Examples of this conduct can range from discriminatory statements or actions to bullying or sexual harassment. Bullying and harassment are two widespread forms of discrimination in Lebanon.

Analysing internal policies after gaining a better understanding of the external environment that employees live in should allow you to understand how discrimination and harassment-sexual or otherwise-can affect the different aspects of one's job, including promotion, salary, job benefits, and access to-or extension ofemployment. It also exposes the prevailing system of power50 in your organisation. 
DID YOU KNOW? BULIKING AND SEXUAL HARASSMENT

3 People/groups who do not fit social and cultural norms are often subjected to bullying and labeling.

- An alleged victim of harassment can be of the same sex as the alleged harasser, though this is not always the case.

- The alleged harasser can be a supervisor, coworker, or a non-employee who has a business relationship with the organisation.

Women, gender non-conforming individuals, and LGBTIQA individuals may be particularly vulnerable to sexual harassment as they may be singled out for their gender or sexual orientation.

- Sexual harassment can take place in person, but also via other means of communication, such as emails, notes, posts, or pictures that can be perceived as offensive or sexually suggestive.

- Sexual harassment includes, but is not limited to, sexual pranks, teasing, jokes, touching, grabbing, or gesturing of sexually suggestive nature. It can also take the form of pressuring coworkers to socialise or giving gifts; supervisors, in particular, should be aware of this. ${ }^{51}$

Notably, both bullying and sexual harassment are the result of abuse of power.

\section{Discrimination}

36 Discrimination [in the workplace] can be very subtle. It can be against gender expression or sexuality, for example. It can also be against single vs. married people; if you're single, you can work late, but if you're married you may go home early, or vice-versa. But when you have a family or children there has to be an unspoken understanding from the organisation that you can leave earlier. At the same time, for those who are not married, it doesn't mean that they don't have a life or other commitments. It's complicated; even being a woman in an all-woman organisation does not necessarily make it a safe haven. ${ }^{52}$

Representative of a prominent feminist civil society organisation in Lebanon 
Below are some questions to help you conduct your internal context analysis:

General internal policy questions: Does your organisation have an established frame for recruitment, career evolution, and dismissal procedures that prevent discrimination? Are recruitment interviews conducted with several interviewers representing all genders? Do your internal policies explicitly state that the sex, sexual orientation, sexual identity, medical file, or physical features must not play a role in preventing someone from being employed by the organisation, receiving a promotion, or getting fired? Do policies describe conflict resolution methods, such as (external) mediation, grievance procedures, and how to file a formal complaint? Do your organisation and its programmes challenge social and cultural norms, work toward gender equity, and promote dialogue on gender issues?
Sexual harassment and bullying: Does your organisation have policies establishing clear procedures (oral/written) to denounce discrimination, such as sexual harassment and bullying? Are staff members aware of these procedures? Do these procedures protect the identity of alleged victims and violators at any stage? Do these policies describe employees' rights and responsibilities throughout the procedure? For example, do procedures include different channels that the alleged victim can turn to? Do you provide counseling services for the victims to talk about their problems? Which steps can an alleged victim follow in case such communication is ineffective or undesirable?

\section{TIPS ON HOW TO CONDUCT THE INTERNAL POLICY ANALYSIS}

Gather documents related to the structure and functions of the organisation-contracts and the code of conduct, for example-but also refer to the project and programme documents, as well as activity reports.

Keep in mind that not all functions and practices within your organisation are explicitly documented, though they should be taken into account in your internal analysis.

Analyse your organisation's internal policies, looking for gaps that may impede the protection of vulnerable persons or the promotion of equity. 
Examine the internal regulations of your organisation: Sort your employees into different teams, with the aim of analysing different internal policy documents or procedures. Ask them to review the clauses and terms of these documents, and to extract the content that is not gender-sensitive and/or does not protect vulnerable persons in the organisation. Make sure to use the questions from previous checklists for guidance.

NOTES 


\section{Communication analysis}

Organisational communication policies are twofold: internal and public. While internal communication policy targets the staff and workers of the organisation, the public communication policy aims at delivering and disseminating the organisation's messages to target audiences and groups. Analysing the language used in communication policies is an essential step in identifying the best means to incorporate gender-sensitive language in your organisation. While this section (Step I) focuses on the analysis of communication, the second step of gender mainstreaming "Define, design, and integrate" (below) highlights practical tips and tricks for implementation.

Organisations should be aware of their public impact, as it affects both target audiences and target groups. If you work in advocacy or with vulnerable groups (women, LGBTIQA, migrant domestic workers), for example, make sure the language you use in your communication does not victimise your target groups and is inclusive in nature.

\section{The full picture}

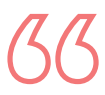
Female migrant domestic workers are often portrayed as inferior; as [if they] are here to serve us, as slaves, or as helpless victims who need to be rescued and sent back home, so that someone else can take care of them. [...] This [way of thinking denies them of their agency]; it fails to acknowledge their full capacities, their own lives; it dehumanises them. ${ }^{53}$ Representative from an organisation working on documenting and fighting discriminatory practices

Organisations' communication material, such as flyers, regulations, booklets, and videos, should be gender-sensitive. Using gender-sensitive illustrations gives greater representation to gender identities often overlooked in society and in the media. Opting for images of women, men, and gender non-conforming individuals who do not comply with traditional gender roles may shift attitudes towards different gender identities by challenging norms and stereotypes surrounding gender.
Therefore, organisations should ask themselves the

- What message is this communication material trying to convey?

- How will this message impact people that are represented therein?

- How will the message impact those who are not represented therein?

Within the organisation itself, staff members should be aware of how their communication can affect their colleagues. For example, statements that can be perceived as condescending and degrading towards a particular gender should be avoided, as they reinforce stereotypes. These statements can be as obvious as "women are not as good as men at negotiation," or as subtle as "be gentle when you tell her the news."

Moreover, employees must also be wary of the fact that communication strategies, while targeting one group, might (unintentionally) exclude another. The same applies for communication amongst employees or target groups. For example, while addressing a group composed of individuals with different gender identities, the expression "OK guys, listen up," unintentionally discriminates against women and gender non-conforming individuals.

Therefore, employees should always ask themselves:

- What kind of oral and written language is used in the workplace? Does the language used by your team reinforce gender stereotypes?

- Can the language used be perceived as hurtful by any member of your team?

- Does the language used in your organisation reject any gender identity?

Aside from explicitly preventing stereotyping and discriminatory statements, organisations should also be aware of patriarchal language structures used in both public and internal communication. 


\section{"SPACE IN IANGUAGE"}

Language is imbued with patriarchal constructions and discourses, and can thus be gender-insensitive at times. This is because male-dominated structures in language convey stereotypes and preserve patriarchal structures in everyday interactions.

Many a time, the pronoun "he" and suffix "-man" are used in language to speak about women, men, and non-conforming individuals. For example, in Arabic, as in many other languages, the "male" form of pronouns is predominantly used, though female-or even neutral-pronouns are available, which provide more "space in language [for] other people to fit in." 54 This male-dominated structure in language is mainly prevalent in other languages such as English, Spanish, and French.

Male pronouns and suffixes are often used in a "gender-neutral" way. However, using these pronouns in this way upholds power relations between women, men, and gender non-conforming individuals, as they silence women and non-conforming individuals in language. Organisations should thus keep in mind the importance of space in language when communicating, both publicly and internally. 
Along with the above, below are some questions to help get you started with your communication analysis:

Does the organisation use genderneutral terms and images in all its public/external communication and visual material?

Does this also apply to internal communication, such as the Code of
Conduct, statutes and bylaws, and other fillable forms?

Do employees and target groups use gender-sensitive language amongst themselves?

\section{TIPS ON HOW TO CONDUCT A COMMUNICATION ANALYSIS}

Conduct interviews or anonymous surveys with employees to see if they have ever been victims of gender-insensitive speech, and to comprehend their understanding of gender-sensitive communication.

Analyse the language used by employees in both formal and informal settings, such as during meetings, at lunch, in the office hallway, or during events. Keep track of gender-insensitive incidents; these can serve as examples during Gender Sensitivity workshops, which you may organise to raise awareness among employees.

Analyse your communication and visibility strategy to ensure gender diversity and inclusivity in public resources and publications, as well as in appearances in public events. 
Take a flyer or any type of documents produced by your organisation and identify all the expressions, words, and images that are not gender-neutral.

ᄂ_ E.g.: the terms "mother" and "father" can be replaced by "parents;" "ladies and gentlemen" is interchangeable with "employees;" "husband" and "wife" can be replaced by "partner."

ᄂ Similarly, images and photographs should follow the same logic, and portray people from a variety of genders in different positions, such as policemen but also police women.

At the end of this exercise, share the results with your team, and discuss how they could use more gender-sensitive terminology in their work.

Q In a team meeting, appoint two people to note down the following without notifying the others that they are doing so:

ᄂ What gender-biased words or expressions are used by the team to describe women and men?

ᄂ What gender-neutral vocabulary is used?

You can conduct this exercise occasionally to see if the team members' language evolves in a gender-neutral way. At the end of this exercise, share the results with your team, and discuss how they could use more gender-sensitive terminology in their work.

Q Think of examples of gender-insensitive behaviour or statements that occur in your work environment. Try formulating a response to them using the following steps:

ᄂ Describe gender-insensitive expressions/statements used in your workplace.

ᄂ Explain how such expressions may affect other members in your team.

ᄂ As a group, think of a gender-sensitive formulation for these expressions/statements. 


\section{Needs assessment}

An important part of gender equity is recognising the differences between women, men, and gender non-conforming individuals' needs, as well as the barriers they face in the workplace. In order to do this, you must conduct a needs assessment. More specifically, a needs assessment can help to identify how women, men, and gender non-conforming individuals are affected by their positionality in society. It can also permit the identification of opportunities that can help these individuals improve their status-both at work and in a broader context. Moreover, a needs assessment highlights the challenges that might exist around women's, men's, and gender non-conforming individuals' participation in various activities or decision-making processes.

Conducting a needs assessment will allow you to ensure equality for all staff members by identifying existing gaps within your organisation, so that you can then create a "gender information management system," which could be utilised in your organisation's strategic planning (see Step II: Define, design, and integrate).

Notably, the needs assessment should address not merely employees' needs within the working space, but also their personal needs with regards to their gender.
In simpler terms, internal needs are directly linked to the workplace and work environment. For example, if separate bathrooms for women and men are available, there should also be a separate bathroom for gender non-conforming individuals. Another solution would be to have shared bathrooms for all employees. This is one way to increase integration of the different gender identities in the workplace, and to express the organisation's will to be more inclusive.

In order to be gender-sensitive, organisations should also take into consideration external factors that extend beyond the workplace, or external needs. These needs have to do with one's identity as separate from being an employee, such as being a mother. For example, in order for employees to have a better work-life balance, your organisation may be flexible in terms of working hours, allowing employees to work from home when they need to (such as when they need to pick children up from school, take medical appointments, perform house maintenance, etc.). Another practical example is to provide a safe space in the organisation where mothers can breastfeed their infants, or to facilitate a children's daycare within the organisation for working parents. 
Below are some questions to help get you conduct your needs assessment :

Is the organisation aware of employees' needs?

Is the organisation responsive to employees' internal needs? For example, are gender-neutral bathrooms available?
Is the organisation taking external needs into consideration? For example, is there a place where women can breastfeed their infants, if necessary? Is childcare available? Are working hours flexible? Are parental leave, family leave, and emergency leave available for all employees, regardless of their gender?

\section{TIPS ON HOW TO CONDUCT YOUR NEEDS ASSESSMENTS}

Make a list of internal and external needs that your employees may have before conducting the needs assessment.

Keeping in mind the quantitative and qualitative gender analysis methods discussed at the beginning of this module, develop tools to collect gender information on an organisational level periodically.

When conducting the needs assessment, preserve anonymity to encourage employees to share as much information as possible. It should also include rating scales to measure degrees of approval or disapproval.

Be discreet when employees share their needs with you; take your employees' needs seriously.

You can include your needs assessment in your baseline study (see section 3.1: Baseline Study). 
Design and create a short electronic or print questionnaire to be filled out by employees individually, in order to collect information about their gender needs. Examples of fields and questions in the questionnaire include:

ᄂ Age and gender identification fields

ـ Do you feel you have equal access to the organisation's resources? What other resources do you wish to have access to? (Provide examples, such as access to medical and psychological support, and compliance officers. Add an empty field for additional answers.)

ᄂ Is your organisation meeting your general needs? If not, why?

ـ What professional skills do you wish to acquire? Does the organisation provide you with opportunities to acquire these skills?

ـ Do you feel that you are able to express your voice, thoughts, and opinions within your organisation?

ـ How is diversity represented at the organisation? Do you feel there is a culture of acceptance of differences? What improvements would you like to see?

ᄂ Do you feel that the organisation provides conflict resolution channels and protection against judgement and discrimination? 


\section{1}

\section{Implementation: Define, design, and integrate}

Once you've conducted the gender analysis, the second step towards achieving gender mainstreaming consists of defining, designing, and incorporating gender mainstreaming in organisational strategies, communication policies, internal policies, programmes and projects, as well as budgets. These are the entry points for introducing new changes that meet the needs of women, men, and gender non-conforming individuals in your organisation.

\section{Gender mainstreaming at the organisational level}

The internal and external gender analysis (see Step 1 of this manual) help the organisation to identify the gaps constraining gender equity, and to define new measures for integrating gender mainstreaming practices in its strategic planning. The task at hand now is to reformulate and redesign a clear organisational mission and vision, as well as clear priorities, target groups, and objectives, all of which should reflect gender mainstreaming. ${ }^{55}$ In this step of the process, your organisation should set a goal to be achieved within a particular stretch of time, specifying objectives for each (or multiple) year(s). The outcome of this stage should be the development of more inclusive and gender-sensitive organisational strategies. One of these strategies may incorporate positive discrimination in your organisation by favouring one employee over another based on their gender, ethnicity, age, marital status, or gender identity. Positive discrimination is often used to empower those who often lack representation, and are treated unfairly in the workforce.

The following sections will further show how different aspects of organisational strategies can reflect gender mainstreaming. 


\section{Internal policies and accountability}

Now you know how to analyse internal policies and

bylaws (see section 1.3.1 for more information on Internal Policy Analysis), and are familiar with the different kinds of discrimination that you should focus on in order to gender mainstream. The following section will highlight the methods you can use to make your internal policies more inclusive, and to provide accountability channels:

- Rules and regulations

- Awareness programmes

- Gender diversity

- Gender-sensitive leadership

- Gender-sensitive performance appraisals

- Equal pay for all employees

- Safe spaces

- Accountability measures

Internal policies are a powerful way to create a safe work environment. By formulating rules and regulations the organisation can determine what will be considered as acceptable or unacceptable behaviour among employees. These policies should make explicit mention of sexual harassment, bullying, and power abuse. (See section 1.3.1: Internal Policy Analysis for more information on sexual harassment or bullying.)

Discriminatory acts that manifest in the form of sexual harassment, bullying, and power abuse, can be prevented by implementing awareness programmes (communication campaigns, training sessions, etc.) and promoting gender diversity across different levels and departments within the organisation. Gender diversity ensures that all gender identities are represented in decision-making positions, as well as public roles (e.g. spokesperson, field work, etc.). ${ }^{56}$ Furthermore, it is important to be fully aware of gender roles and stereotypes. For example, is your organisation appointing women to social work, or assigning them tasks related to children? Are men charged with financial tasks, or tasks that require negotiation? Resisting traditional gender roles is a good way to overcome gender stereotyping in the division of labour within your organisation.
Gender-sensitive leadership is another approach that helps ensure gender diversity within your organisation. People in leadership positions often have significant influence on the attitudes, behaviours, and beliefs of other members of the organisation, which impacts the planning of activities and projects. Gender-sensitive leaders should thus push the team to adopt a gender perspective at the core of the organisation's values and their work.

\section{Representation and diversity}

$Z$ Some organisations advocate gender-related issues [...], but when these organisations are represented in a meeting or abroad, it's only men. [...] Some organisations don't have a gender policy or gender perspective at all, but you'll still find some women in decision-making positions. When this is the case, these women are often the daughters, sisters [or wives] of one of the founders, and they play the same role that men would otherwise play: they silence their colleagues. So they are not really challenging the status quo. But I think these [women] can bring about change if they can understand what's going on, and the role they can play in bringing about this change. 57

Representative of an international development organisation with a special focus on gender issues

Gender is also about diversity; people should come from different backgrounds. It's healthier if there are different personalities, people coming from different religious or social backgrounds. [...] Regardless of whether or not some staff members belong to the LGBTIQ community, for example, our work setting needs to welcome diversity and gender-sensitivity. [...] It's also important to communicate, whether in the job announcement itself or during the job interview, that people from all backgrounds are welcome to apply. Some women assume that they might not get hired if they're pregnant or newlywed out of fear that the employer or organisation might think that they would be quite absent, so it's important to dispel these misconceptions. 58 Representative of an international development organisation with a special focus on gender issues 
HOW TO ENSURE BQUAL PAY?

Ensuring equal pay is vital to

guarantee gender equity within an

organisation. One way of ensuring equal

pay is for your organisation to develop and

implement a rigid structured salary scale.

Rigid salary scales are favoured by labour unions since they prevent discrimination based on gender, age, race, and religion,

among others. As such, this type of salary scale classifies different positions in a

organisation into set levels. Within these

levels are ranges that allow for a minimum

and maximum pay range.

Notably, employees are placed into a

specific pay scale range based on their:

- Years of experience in the sector

- Level of education

- Skillset needed for the position

As such, when a new position opens up or is created, it is placed into a specific level. This helps to bypass a hiring manager's inadvertent bias when determining a salary for an interviewee. Once an employee is hired, their salary is not determined by their past salary, nor by their capacity to negotiate, but rather, by whether or not they meet the position's requirements.

Moreover, a rigid structured salary scale, coupled with the relevant corresponding policies and procedures, can help to ensure a fair salary growth for all employees, promoting transparency in the process. It can thus limit structural inequalities in salaries by ensuring that the organisation provides equal pay for equal work.
In addition to ensuring an equal division of labour and the presence of different genders in leadership positions, performance appraisals should also refrain from applying stereotypes and biases to staff and employees of different genders, age, colour, etc. Performance appraisals are periodic assessments that evaluate one's job performance. Employers and employees alike should be wary of not stereotyping others or themselves during these assessments. Common stereotypes can include, for example, the assumption that women and senior employees are less productive.

Employees that are in the same position should thus have access to the same benefits, regardless of their gender. In addition, organisations should ensure equal pay for all employees.

In addition to the above, make sure your work environment is a safe space, where employees feel free to express themselves without any constraint or fear. Safe work environments make it possible for employees to discuss the discrimination they encounter and raise the issue with the employer.

Moreover, it is important to establish accountability measures for when these rules are broken, in order to ensure that discriminatory behaviour is handled with fairness and clarity. Accountability measures should be detailed and shared as part of the organisational code of conduct and regulations so that all staff members know what steps to take should they need to file a complaint. In addition, we recommend running mandatory trainings on ethics, or more specifically, gender. 


\section{Addressing external needs: A better work-life balance}

Conducting the needs assessment (see section 1.5: Needs assessment) should provide you with insights on your employees' external needs, that is, recognising the responsibilities of employees outside the work context. Accordingly, organisations should "implement, promote, and evaluate policies related to work-life balance." 59 This can include allowing flexible working arrangements - which can be beneficial for people who might need to be out of the office during regular 8:0018:00 working hours_or providing male employees with a paternity leave, even if it is not required by law. The latter measure is an indicator that the organisation promotes equal distribution of childcare duties, 60 as it relieves women from the responsibility of being the sole "caregiver," allowing them to take look after their health and maintain their career. ${ }^{61}$

\section{How to cater to external needs? \\ One of our employees is a working mother.}

From the beginning, she told us, 'I have to leave at a certain time, because I have to pick my children up from school.' As a feminist organisation, we said, 'Of course, you can leave at this time; beyond that point, you can follow up on your work by email.' Organisations should have this flexibility. 62

Representative of a leading women's organisations working in Lebanon 
Below are some questions that can guide you in implementing gender-sensitive internal policies in your organisation:

General: Is there a policy to denounce inappropriate behaviour? Are all employees aware of your internal regulations and policies? Have you established awareness programs? How does your organisation avoid stereotyping in the division of labour? Which measures should be taken to establish equal treatment and opportunities for a promotion?

\section{Gender-sensitive leadership: How can} you increase the number of women or gender non-conforming individuals occupying in leadership positions in your organisation? How do the leaders in your organisation promote inclusivity and take the input of women and gender non-conforming individuals into consideration in their work?

Performance appraisals: Is your organisation conducting regular performance appraisals? What gender-sensitive methods are used in these processes? Are employees' new positions, salaries, tasks, etc., determined by gender-sensitive performance appraisals?
Equal pay for employees: How does your organisation ensure that it offers equal pay for equal work for all employees? Does your organisation have a rigid salary scale? Is your organisation transparent about the process of defining salaries?

Safe work environment: Does your organisation have a safe environment where work-related concerns and gender issues can be addressed? Does your organisation ensure anonymity to employees who report discriminatory behaviour, as well as to alleged perpetrators?

Accountability measures: How does your organisation investigate claims? What accountability mechanisms does your organisation employ to ensure employees are held responsible for discriminatory behaviour? How can these mechanisms ensure the wellbeing of groups that are discriminated against in the workplace? 
Employees should be encouraged to denounce gender stereotyping and discriminatory statements in the workplace. This can be done in a friendly and respectful manner by explaining why it is important to not stereotype others in the office, and how gender-insensitive comments can inhibit teamwork and the team's overall level of comfort with one another.

Policies should respond to employees' external needs. Use the needs assessment you performed (See section 1.5: Needs Assessment) to formulate responses.

Even when cases of discrimination are solved at an individual level, without the organisation's mediation, employees should report the incident for organisational records.

Employees should formally report incidents to line-managers or any other department in charge of handling the form of discrimination so that measures can be taken to ensure that no further harassment occurs. The organisation can also choose to investigate the incident, call a hearing for the (alleged) violator, or fill a formal complaint against the offender, and/ or take the appropriate disciplinary measures against the perpetrator.

Develop a communication channel to report discrimination to the board of your organisation (e.g. via periodic discrimination memos or monthly updates).

Develop a rigid pay scale suitable for your organisation, while incorporating measures of positive discriminations, such as a quota to facilitate the access of women and gender non-conforming individuals to positions usually occupied by men in the organisation. 
Along with your team, draft internal policies and accountability mechanisms that you could implement in your organisation:

ـ How can employees file a formal complaint if they experience discrimination? Who should they file the complaint to?

ᄂ How can your organisation take the necessary measures to ensure that harassment allegations are promptly and impartially investigated and addressed?

ـ What right and responsibilities do individuals have throughout the procedure? How can you protect the identity of alleged victims and violators at different stages in the process?

L How can you ensure that the current and future staff members are aware of these procedures?

2 As a group, think of some instances when your organisation can employ "positive discrimination" policies for greater gender representation and inclusivity. 


\section{Developing inclusive communication policies}

As has previously been outlined, gender-sensitive language is pivotal for your organisation's internal and public communication information dissemination (see section 1.4: Communication Analysis). Using your communications analysis from Step I, you can now begin to restructure your communication strategy to begin Step II: Implementation. Read the examples below to help you get you started:63

\section{Use neutral nouns and pronouns}

Traditional:

The organisation reserves the right to terminate his contract in the event of serious professional misconduct or negligence affecting his work.

\section{Gender-sensitive:}

The organisation reserves the right to terminate the consultant's contract in the event of serious professional misconduct or negligence affecting the work.

\section{Traditional:}

Dear Sirs/Madams,

Gender-sensitive:

To Whom it May Concern,

Change to plural

Traditional:

The project officer should hand in his narrative reports by the end of the month.

Gender-sensitive:

Project officers should hand in their narrative reports by the end of the month.

\section{Use the passive voice}

\section{Traditional:}

The project officer should hand in his narrative reports by the end of the month.

\section{Gender-sensitive:}

Narrative reports should be handed in by the project officer by the end of the month.
In addition to appropriate phrasing, organisations' images and communication material (flyers, regulations, booklets, videos, etc) should also be gender-sensitive. Using gender-sensitive illustrations is crucial as it gives greater representation to gender identities often overlooked in society and the media. Choosing images of women, men, and gender non-conforming individuals that do not comply with traditional gender roles may help to shift common attitudes towards different gender identities by challenging norms and stereotypes surrounding gender. For example, images displaying a female president can help others envision this into a reality.

\section{Advocacy efforts: Things to keep in mind}

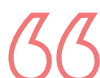

A bad example of advocacy efforts would be if all our videos about domestic workers [...] [showed] migrant domestic workers being beaten up on the streets, highlighting the severity of the abuse. [...] It would be better to show how they are helping one other, helping the community, opening space to [have] discussions about their conditions. So, a good example would be showing [the] abuse, and at the same time, acknowledging the good.64 Representative from an organisation working on documenting and fighting discriminatory practices

Moreover, both written ("language") and oral ("voice") communication must be addressed at both the organisational and individual levels: "If individuals themselves are not aware of these issues, then [organisations] won't be able to address them [...], either."65 Organisations should thus raise awareness among employees regarding gender-related issues by organising workshops, team discussions, and conferences centred on gender awareness.

Make sure you modify your internal (policies, emails, contracts, etc.) and public/external (event flyers, public resources, website, etc.) materials to make your communication more gender-sensitive and inclusive. 
Share the results of the communication analysis outlined in Step I with your team.

Take your organisation's unwritten rules into account when you modify your internal policies.
Let women and gender non-conforming individuals sit in central positions during meetings to give them more chances to speak and be heard.

\section{DEVELOPING INCLUSIVE COMMUNICATION POLICIES EXERCISE: SELF-ASSESSMENT}

As a group, reflect on how you can change your organisation's communication policies. This can be done over several non-consecutive days, in order to increase the team's awareness on related issues over time. 


\section{Gender mainstreaming in programmes, projects, and budgets}

Integrating gender mainstreaming into projects begins during the design phase. The implementation of gender-sensitive projects is twofold, as organisations must ask themselves:

How can I be gender-sensitive in designing this project?

-What are the goals of this project?

-What are the expected results?

-What resources will be allocated to this purpose, and how will they be distributed?

- Try to include at least one specific outcome/indicator per project focusing on gender equity. 66

How can I be gender-sensitive in implementing this project?

- Who will be in charge of the project?

- How will the different responsibilities be shared among team members?

To that end, an important part of gender mainstreaming is to actively involve all relevant employees, regardless of their gender, in the design process of new projects.

Once you have considered the elements above, you can begin to define your programmes or projects based on outcomes from the Gender Analysis (Step I):

\section{Start with formulating a clear and specific project} objective.

E.g.: Youth will be better represented in local and national politics in Lebanon within 5 years.

Develop a gender-sensitive strategy; a long-term plan to achieve the objective.

E.g.: While the project focuses on youth, an organisation may choose to use a strategy of positive discrimination to specifically target women and non-conforming individuals.

It is important to note here, however, that a project can be gender-sensitive without focusing on a particular gender identity. Instead, the project can be genderinclusive at every step of its implementation, thus promoting gender equity indirectly.
Lastly, design an action plan.

This includes defining activities, required inputs,

expected outcomes, effects, indicators, assumptions, and the timeline needed to implement these objectives. These activities should ensure a fair representation and equal participation of all genders.

During the design phase, the objectives, milestones, activities, and action plan of a programme or project can be "engendered." 67 When a project is engendered, it explicitly formulates objectives in a gender-disaggregated manner in order to set goals responding to the needs of each gender identity. In simpler terms, the needs of each gender identity must be reflected in the overall objective. For example, one can replace "facilitate access to education" by "facilitate access to education for women, men, and gender non-conforming individuals," in order to ensure that all target groups from each gender identity benefit from this initiative according to their needs, and reduce the existing gap between women's, men's, and gender non-conforming individuals' access to resources. Therefore, implementing engendered projects does not mean organising projects exclusively for women or gender non-conforming individuals, but rather, including these groups in a melting pot of identities.

In contrast, gender-sensitive projects imply that every step and every aspect of the project is planned and designed with gender dynamics and gender analysis in mind. It also means that people across all gender identities are consulted during the design of the project. For example, even if your organisation is looking for donors for a project, it can choose to ask for funds from gender-sensitive donors. This can be one aspect of gender-responsive budgeting.

As an important part of successfully implementing policies, budgeting is an important tool to promote gender equity. Gender-sensitive budgeting does not mean working on separate budgets for women, men, and gender non-conforming individuals, but rather, ensuring that the way the budget is allocated helps to address specific gender needs. Although, at an organisational level, gender budgeting only leads to small shifts in budget allocations, it is an important 


\section{GENDFR ADVOCACY}

As noted in the previous section,

organisations developing gen-

der-sensitive strategies can promote

equity by implementing projects dealing

specifically with gender issues. These

projects can then be classified as gender

advocacy. Gender advocacy is an activity

through which organisations defend

women and gender non-conforming

individuals, and promote gender equity.

Gender advocacy also includes lobbying

for gender equity at a national level by

advocating for gender-sensitive policies

and budgets, ${ }^{68}$ as budgets can contribute

to the perpetuation of stereotypes and

gender biases. As such, NGOs play an

important role in identifying which groups

are left behind in policies and governmen-

tal budgets. In order to advocate for equal

rights and a more equal distribution of

resources, NGOs ought to coordinate their

lobbying efforts.
Gender budget analysis is a pre-budgeting tool in order to evaluate the potential impact of a project. ${ }^{71}$ It analyses the direct and indirect impact of an organisation's programmes on each gender while assessing their needs using sex-, age-, and origin-disaggregated data, in order to differentiate how budget is spent on different genders. An organisation can respond to the needs identified in the gender budget analysis by reallocating funds to gender-sensitive expenditures.

Some organisations may also decide to only accept gender-sensitive revenues, choosing to work exclusively with partners that are gender-aware.

Gender-responsive budgeting can therefore improve the quality of decision-making processes, contribute to raising awareness, and increase transparency and accountability. It also provides data that can be used in gender advocacy and gender mainstreaming, and introduces mechanisms that require decision-makers to take women's and gender non-conforming individuals' needs into account.

and symbolic change to carry out for organisations seeking to be gender-sensitive. ${ }^{69}$ Moreover, gender budgeting does not lead to greater expenses.

\section{Gender perspective in budgeting}

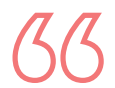

I think it is important to highlight the idea

that you can do gender budgeting for free, or at least within your resources. Let's take the toilet signs, for example: if you have already decided to pay for toilet signs, you can order two, one for men and one for women, but you can also purchase two that only say 'WC.' This won't cost you any extra money. Or, say, you want to buy a table; it will not cost you more to make it a bit higher to make it wheelchair-friendly. Gender mainstreaming can be done without any resources, you just have to be aware of it.70 Representative of an international development organisation with a special focus on gender issues 
Did your team take the data collected during the gender analysis into consideration when designing the project?

How is a gender perspective incorporated in your programmes (objectives, milestones, activities, and action plan of a programme)?

Are all gender identities involved in planning and designing projects, including their presence in discussions and decision-making positions? From a qualitative point of view, this entails that they share their thoughts and experiences, and are listened to.

How can men's involvement in projects not be intimidating for women and gender non-conforming individuals? Can people of different genders speak for themselves, or do they have someone speaking on their behalf?

For projects working directly with target groups, are women and gender non-conforming individuals able to join the programme? If not, what barriers prevent them from doing so?

Does the budget address employees' specific needs? Is healthcare distributed fairly among all employees? Is your organisation working with female contractors, or contractors promoting gender equity, in general? Is your budget allocated in a gender-sensitive way? Are your resources (time, money, spaces, etc.) shared fairly among women, men, and gender non-conforming individuals?
Use the results of your gender analysis (see Step I) to ensure that your project's design integrates all gender identities while responding to their needs.

Take into consideration cultural and religious practices that feed into local gender dynamics, which may put your activities at risk and influence their overall impact (for more information, see section 1.2: External Context Analysis).

Analysis also requires the use of gender-sensitive analysis tools like sex-, age-, and origin-disaggregated data, in order to differentiate their effects on each gender. 
Along with your team members, analyse a project or programme that has yet to be implemented. Discuss how you can make the project/programme gender-sensitive using the checklist above.

NOTES

\section{GENDER BUDGETING EXERCISE: SELF-ASSESSMENT}

Analyse the organisation's revenues and expenditures over the last month with your colleagues. Discuss how your organisation can make future revenues and expenditures more gender-sensitive. Use the checklist above to guide you.

Do the same exercise with a project's budget. 


\section{Monitoring and evaluation}

Monitoring and evaluation (M\&E) are the last steps towards achieving gender mainstreaming. They allow organisations to check if their work is heading in the right direction, and if not, to revise their strategy and make some changes. This can be done by monitoring and evaluating whether the policies, projects, and activities meet their set objectives.

During the M\&E phase of a project, your organisation is continuously monitoring and evaluating the project by conducting punctual assessments. These assessments compare the written project objectives to the actual results taking place during implementation. This can help measure the impact of the project.

The evaluation process can be divided into three moments:

- The midterm evaluation

- The end-of-project evaluation

- The post-project evaluation

Notably, the post-project evaluation is conducted after the end of the project to evaluate the longterm impact of the project.

Monitoring and evaluation processes often coincide, if only partly.

\section{Baseline studies: A tool for monitoring projects}

A baseline study can be conducted at the beginning of a project or programme. This tool serves to monitor your project's evolution by keeping track of the starting point and assessing the impact of a programme by making a new round of data collection.

Both quantitative and qualitative data can be used in baseline studies. You can thus gather genderdisaggregated data through surveys, individual interviews, or focus groups when you need access to personal insight. You can also use administrative documents such as employees' records, the organisation's regulations, budgets, or other material to create a "Gender info management system" that gives you insight into your organisation, its employees, and its work. 


\section{Feedback mechanism}

42

Having a feedback mechanism gives the team and/or the target groups a role in the monitoring and evaluation phase of gender mainstreaming, as they are the first to be affected by the organisation's culture, policies, and new projects. Taking their insights into account is thus necessary in evaluating the issues that have to be addressed in future projects, programmes, or activities. Feedback can also be gathered through surveys or interviews, which can provide insight into employees' attitudes, and whether or not they have integrated a gender-sensitive code of conduct.

\section{Insights}

3 I've faced discrimination because of my gender. If you're a woman, you might not be taken very seriously if you look fairly young, even if you are working in a women's organisation or attending a related event. If you're naturally soft-spoken, you might be discouraged or not allowed to read a statement in public. What I do in these cases is face it. I either respond immediately, or discuss it with the person in question later. It is important to reach an agreement or receive an apology. Sometimes, people feel that if the person representing the organisation at an event is a gender non-conforming person, it gives the organisation a good image. These are things we've dealt with and talked about. They happened and we learned from them because we talked about them and raised our voices. ${ }^{72}$

Representative of a prominent feminist civil society organisation working in Lebanon on discrimination and positive discrimination 
Below are some questions to help you begin the monitoring and evaluation process:

Do employees' roles and responsibilities "on paper" match the ones they actually handle?

Did the organisation's regulations evolve to respond to a certain evaluation or needs assessment? Did the organisation's hierarchy and structure evolve? If so, how?

In what ways did the project impact the target groups?

Is there an observable change in the skills and knowledge of the organisation's staff? Did the relationships among the team members evolve? If so, in what ways? How do the organisation's employees feel about the tasks they are given and the environment they work in?

Was the project well managed? If not, what went wrong? Why? What were the strengths and weaknesses of the strategy and the evaluation tools? Did the programme meet its objectives? If not, which objectives were partly met, or not? Why?

\section{TIPS FOR MONITORING AND EVALUATION}

Gender budget analysis can be used to monitor and evaluate how different groups may be impacted by a project/ programme.
See Checklist from Gender 101 and Step I Gender Analysis to develop a baseline questionnaire. 


\section{Conclusion}

Gender mainstreaming has increasingly been the subject of evaluation and critique over the last two decades. One of the main critiques is that gender mainstreaming in institutions (organisations, government bodies) has lost its political dimension, which is deeply rooted in feminism. ${ }^{73}$ Today, however, gender mainstreaming is viewed more as a technical process with steps and procedures. ${ }^{74}$

Another critique of gender mainstreaming is that while it is integrated in institutional and organisational structures, it usually does not reach private or personal spheres where inequality and oppression often remain intact. 75

As such, when using this manual, your organisation should take into consideration the philosophy behind gender mainstreaming, as to both implement the given steps and understand the context within which they were devised.

By creating a better understanding of gender mainstreaming in organisations in Lebanon, this manual hopes to provide the reader with practical tips and tools to enhance gender equity, beginning with analysis, and moving on to implementation, and monitoring and evaluation.

As such, this manual sheds light on how gender can affect one's access to rights, resources, and opportunities. It should be noted that the tools in this manual should be tailored to the organisation's mission, vision, and specialisation. 


\section{Endnotes}

1 Interview by Lebanon Support, Beirut, 8 June 2017.

2 Interview by Lebanon Support (1), Beirut, 7 July 2017.

3 United Nations, "The Universal Declaration of Human Rights," Paris, United Nations General Assembly, 1948, available at: http://www.un.org/en/universal-declaration-human-rights/ [last accessed 7 June 2017].

4 Organisation for Economic Co-operation and Development, "Gender equality and women's rights in the post-2015 agenda: A foundation for sustainable development," OECD Contributions to post-2015 Reflections Series, Paris, OECD Publishing, 2015, available at: https://www.oecd.org/dac/gender-development/ POST-2015\%20Gender.pdf [last accessed 16 June 2017].

5 United Nations, "Report of the World Conference to review and appraise the Achievements of the United Nations Decade for Women: Equality, Development and Peace," New York, United Nations, 1986, available at: http://www.un.org/documents/ga/conf177/nfls/thirdwcw1985-nfls.htm [last accessed 30 October 2017].

6 United Nations Office of the Special Adviser on Gender Issues and Advancement of Women, "Gender Mainstreaming. An Overview," New York, United Nations, 2002, p. 1, available at: http://www.un.org/womenwatch/osagi/pdf/e65237.pdf [last accessed 2 June 2017].

7 Cited in: Jenny Riley, "Some reflections on gender mainstreaming and intersectionality," Development Bulletin, Canberra, Australian National University, 2004, Vol. 64 (1), p. 82-86, available at: https://crawford.anu.edu.au/rmap/devnet/ devnet/db-64.pdf [last accessed 16 June 2017].

8 Stéphanie Farrior, "Human Rights Advocacy on Gender Issues: Challenges and Opportunities," Journal of Human Rights Practices, Oxford, Oxford University Press, 2009, Vol. 1 (1), p. 83-100, available at: https://academic.oup.com/jhrp/ article/1/1/83/2188706/Human-Rights-Advocacy-on-GenderIssues-Challenges [last accessed 16 June 2017].

9 Ibid., p. 1.

10 For more information on gender mainstreaming in general, see: Department for International Development, "The Gender Manual. A Practical Guide," London, DFID, 2008, available at: http://webarchive.nationalarchives.gov.uk/+/http:/www.dfid. gov.uk/Documents/publications/dfid-gender-manual-2008.pdf [last accessed 16 June 2017].

11 The manual herein provides a synthesised selection of the most frequently used gender-related terms and definitions. For a more comprehensive list, see the cited references.

12 Lebanon Support, Gender Dictionary: Traveling Concepts and Local Usages in Lebanon, Beirut, Lebanon Support, 2016, p. 23.

13 Lebanon Support, op. cit., 2016.

14 United Nations Commission on the Status of Women, "Convention on the Elimination of All Forms of Discrimination against Women - Article 1," New York, United Nations General Assembly, 1979, available at: http://www.un.org/womenwatch/daw/cedaw/text/econvention.htm [last accessed 16 June 2017].
15 Cited in Nelien Haspels, Zaitun Mohamed Kasim, Constance Thomas and Deirdre Mc Cann, "Action against Sexual Harassment at Work in Asia and the Pacific," Bangkok, International Labour Office, 2001, p. 21, available at: http:// www.ilo.org/wcmsp5/groups/public/---asia/---ro-bangkok/ documents/publication/wcms_bk_pb_159_en.pdf [last accessed 23 June 2017].

16 UK Government, "Bullying at School," Website, GOV.UK, available at: https://www.gov.uk/bullying-at-school/bullying-a-definition [last accessed 23 June 2017].

17 Hazel Reeves and Sally Baden, "Gender and Development: Concepts and Definitions," Brighton, BRIDGE (development - gender), 2000, available at: http://www.bridge.ids.ac.uk/ sites/bridge.ids.ac.uk/files/reports/re55.pdf [last accessed 31 October 2017].

18 Ibid., p. 33.

19 Lebanon Support, op. cit., 2016.

20 Ibid.

21 Ibid., p. 29.

22 European Institute for Gender Equality (EIGE), "Institutional Transformation; Gender Mainstreaming Toolkit," Luxembourg, Publications Office of the European Union, 2016, available at: http://eige.europa.eu/gender-mainstreaming/toolkits/ gender-institutional-transformation/step-4-developing-gender-mainstreaming-strategy-and-working-plan[last accessed 2 November 2017].

23 Interview by Lebanon Support, Beirut, 22 May 2017.

24 For a definition of "gender non-conforming," see section Gender 101 of this manual. Collecting non-binary gender- and transgender-inclusive data has been on the rise internationally, and best practices are constantly refined and developed to encompass as many gender identities as possible. See United Nations, "Gender identity-Developing a statistical standard," New York, Department of Social and Economic Affairs - Statistics division, 2015, available at: https://unstats.un.org/ unsd/class/intercop/expertgroup/2017/AC340-22a.PDF [last accessed 1 November 2017]

25 Greta Bauer, Jessica Braimoh, Ayden Scheim, and Christoffer Dharma, "Transgender-inclusive measures of sex/gender for population surveys: Mixed-methods evaluation and recommendations," Westminster, PLOS One, 2017, Vol. 12 (5), available at: http://journals.plos.org/plosone/article?id=10.1371/journal. pone.0178043 [last accessed 1 November 2017].

26 Lebanon Support, Gender Dictionary: Traveling Concepts and Local Usages in Lebanon, 2016.

27 Kimberly Crenshaw, translated by Oristelle Bonis, "Cartographie des marges, intersectionnalité, politiques de l'identité et violences contre les femmes," Cahiers du Genre, 2005 [1994], Vol. 39 (2), p. 51-82, available at: https://www. cairn.info/revue-cahiers-du-genre-2005-2-p-51.htm [last accessed 7 August 2017]. 
28 "Gender non-conforming" is a term used by people who don't identify with gender identities that are purely "male" or "female." Statistically, it is highly unlikely for every organisation to have an equal number of men, women, and gender non-conforming individuals. Therefore, we recommend your organisation to adopt a fair recruitment process regardless of applicants' identities.

29 Juliet Hunt, "Introduction to gender analysis concepts and steps," Development Bulletin, Canberra, Australian National University, 2004, Vol. 64 (1), p. 78-79, available at: https:// crawford.anu.edu.au/rmap/devnet/devnet/db-64.pdf [last accessed 16 June 2017]; Department for International Development, op. cit., 2008.

30 Interview by Lebanon Support with an international organisation working on gender issues in Lebanon (1), Beirut, 7 July 2017.

31 Interview by Lebanon Support, Beirut, 22 May 2017.

32 Department for International Development, op. cit., 2008.

33 Patriarchy is a social system-individuals organised into groups that have specific functions-in which men are entitled to exercise domestic and political authority upon the rest of the household and community. This system is also referred to as "abawiya" in Arabic. See: Diakonia, "إدماج مفاهيم ومقاربة حقوق النساء والمساواة الجندرية في مشاريع وبرامج عمل المنظمات " Beirut, Diakonia, 2010, p. 13; Lebanon Support, op. cit., 2016.

34 Lebanon Support and the Lebanese Women Democratic Gathering, "Women's Achievements in Lebanon," Website, Civil Society Knowledge Centre, 2 May 2017, available at: http://civilsociety-centre.org/gen/women_mvt/4939 [last accessed 16 June 2017].

35 Marie-Noëlle Abi Yaghi, L'altermondialisme au Liban: un militantisme de passage. Logiques d'engagement et reconfiguration de l'espace militant (de gauche) au Liban, Thèse de science politique, Université de Paris-La Sorbonne, 2013.

36 Riwa Salameh, "Gender Politics in Lebanon and the Limit of Legal Reformism," Civil Society Knowledge Centre, Beirut, 2014, available at: http://civilsociety-centre.org/paper/gender-politics-lebanon-and-limits-legal-reformism-en-ar [last accessed 19 June 2017].

37 Nizar Hassan, "Lebanon ranked eighth worst country for gender equality," The Daily Star, 29 Otcober 2014, available at: http://www.dailystar.com.lb/News/Lebanon-News/2014/Oct29/275721-lebanon-ranked-eighth-worst-country-for-genderequality.ashx [last accessed 16 June 2017].

38 Lebanon Support and the Lebanese Women Democratic Gathering, op. cit., 2017.

39 An exception is made for children of unmarried mothers. In case these children still do not have a nationality after one year, they can obtain the Lebanese nationality from their mother. See: Lebanon Support and the Lebanese Women Democratic Gathering, op. cit., 2017.

40 Ibid.
41 Ibid.

42 Ibid.

43 Ibid.

44 International Labour Organisation, "International Labour Standards on Maternity Protecion," Website, ILO, available at: http://ilo.org/global/standards/subjects-covered-by-international-labour-standards/maternity-protection/lang--en/index. htm [last accessed 8 June 2017].

45 See: Myriam Sfeir, "Time to Change Lebanese Law That Offers Rapists Marriage to Survivors," News Deeply, 11 May 2017, available at: https://www.newsdeeply.com/womenandgirls/ community/2017/05/11/time-to-change-lebanese-law-thatoffers-rapists-marriage [last accessed 23 June 2017].

46 Interview by Lebanon Support, Beirut, 24 May 2017.

47 Interview by Lebanon Support, Beirut, 7 July 2017.

48 Bureau de la documentation libanaise et arabe, "L'argus de la législation libanaise. Traduction trimestrielle des principaux textes législatifs libanais," Beirut, Bureau de documentation libanaise et arabe, 2010, Vol. 56 (1), available at: http:// www.ilo.org/dyn/travail/docs/710/Labour\%20Code\%20 of $\% 2023 \% 20$ September\%201946\%20as\%20amended. Publication\%202010.pdf [last accessed 21 June 2017].

49 Susan Marine, "Strategies for Making Workplaces More LGB Inclusive," Massive Open Online Course, Coursera, 2017, available at: https://www.coursera.org/learn/gender-sexuality/lecture/UMPdg/strategies-for-making-workplaces-more-lgb-inclusive [last accessed 4 August 2017].

50 Clyde Soto, "Violencia de género y hacia las mujeres," Curso de formación y actualización sobre género y derechos de las mujeres, Diakonia, 2017.

51 US Department of State, "Sexual Harassment Policy," Website, US Department of State Diplomacy in Action, available at: https://www.state.gov/s/ocr/c14800.htm [last accessed 23 June 2017].

52 Interview by Lebanon Support, Beirut, 8 June 2017.

53 Interview by Lebanon Support, Beirut, 17 May 2017.

54 Interview by Lebanon Support with a representative of a local organisation working on documenting and fighting discriminatory practices, Beirut, 17 May 2017.

55 Emily Gantz McKay, "Strategic Planning; a Ten Step Guide," Mosaica, 2001, available at: https://siteresources.worldbank. org/INTAFRREGTOPTEIA/Resources/mosaica_10_steps.pdf [last accessed 2 November 2017].

56 Interview by Lebanon Support (1), Beirut, 7 July 2017.

57 Department of Gender and Social Development, "Training Manual on Gender Mainstreaming," Nairobi, Ministry of Gender, Children, and Social Development, 2008, available at: http:// www1.uneca.org/Portals/ngm/Documents/Kenya-GenderTraining-Manual.pdf [last accessed 16 June 2017].

58 Interview by Lebanon Support (2), Beirut, 7 July 2017. 
59 "UN Swap. An accountability framework to mainstream gender equality and the empowerment of women across the UN system," New Tork, UN Women, 2017, available at: http://www. unwomen.org/-/media/headquarters/attachments/sections/ how\%20we\%20work/unsystemcoordination/un-swap-brochure.pdf?la=en\&vs=1831 [last accessed 14 November 2017].

60 Interview by Lebanon Support with representative of a leading women's organisation working in Lebanon, Beirut, 22 May 2017.

61 Lauren Holter, "Paid Paternity Leave Is Essential For Gender Equality. Why United States Is Taking So Long To Catch On?," Bustle, 18 June 2015, available at: https://www.bustle.com/ articles/90820-paid-paternity-leave-is-essential-for-gender-equality-why-is-the-united-states-taking-so-long [last accessed 5 June 2017].

62 Interview by Lebanon Support, Beirut, 22 May 2017.

63 Gender and Development Committee Gender and Development Committee, "Questions \& Answers. Use of Non-sexist Language in all Official Documents, Communications and Issuances," Quezon City, National Statstics Office, 2005, available at: https://psa.gov.ph/sites/default/files/attachments/aodao/ article/Q\%20\%26\%20A_Use\%20of\%20Non_Sexist\%20 Language.pdf [last accessed 14 November 2017].

64 Interview by Lebanon Support, Beirut, 17 May 2017.

65 Interview by Lebanon Support, Beirut, 17 May 2017.

66 UN Women recommends to include at least one specific outcome/expected accomplishment and one specific indicator. See UN Women, op. cit., 2017.

67 Trocaire, "Gender mainstreaming resource pack: a practical guide for programming," Maynooth, Trocaire Head Office, 2010 , p. 19, available at: https://www.trocaire.org/sites/default/ files/resources/policy/gender-mainstreaming-resource-pack. pdf [last accessed 23 June 2017].

68 Helena Hofbauer Balmori, "Gender and Budgets: A Practical Tool to Advance Towards Equity," BRIDGE, Brighton, Institute of Development Studies (University of Sussex), 2002, available at: http://www.bridge.ids.ac.uk/sites/bridge.ids.ac.uk/files/Docs/ dgb12.html [last accessed 23 June 2017].

69 Debbie Budlender, "Gender Budgets: What's in It for NGOs," Gender and Development, Abingdon, Taylor \& Francis, 2002, Vol. 10 (3), p. 82-87.

70 Interview by Lebanon Support (2), Beirut, 7 July 2017.

71 Emilie Combaz, "Impact of Gender-Responsive Budgeting," Birmingham, GSDRC Publications, 2013, p. 4-5, available at: http://gsdrc.org/docs/open/hdq977.pdf [last accessed 19 June 2017].

72 Interview by Lebanon Support, Beirut, 8 June 2017.

73 Kirsty Milward, Maitrayee Mukhopadhyay, and Franz Wong, "Gender Mainstreaming Critiques: Signposts or Dead Ends?," IDS Bulletin, 2015, Vol. 46 (4), p. 75-81.

74 Ibid.
75 Oana Crușmac, "Why Gender Mainstreaming is not enough? A Critique to Sylvia Walby's the Future of Feminism," The Romanian Journal of Society and Politics, April 2015, p. 102-17, available at: http://rjsp.politice.ro/sites/default/files/pictures/5_crusmac.pdf. [last accessed November 2, 2017].

\section{Ibid.}




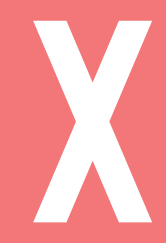

Lebanon Support @ c Beirut, December 2017. 